\title{
TUBAL ECTOPIC PREGNANCY: COMPARATIVE STUDY OF LAPAROSCOPY VS LAPAROTOMY
}

\author{
K. Saraswathi', M. Shailaja Prasad², B. Kiran Kumari ${ }^{3}$ \\ ${ }^{1}$ Associate Professor, Department of Obstetrics and Gynaecology, Niloufer Hospital, Hyderabad. \\ ${ }^{2}$ Associate Professor, Department of Obstetrics and Gynaecology, Niloufer Hospital, Hyderabad. \\ ${ }^{3}$ Civil Assistant Surgeon, Area Hospital, Bhongir, Telangana.
}

ABSTRACT: OBJECTIVE: comparative study of surgical management of ectopic (Tubal) pregnancy.laparoscopy versus laparatomy and its outcome and complications To know the incidence of ectopic pregnancy during the study period and the risk factors for ectopic pregnancy.

METHOD: In this study 50 cases of ectopic pregnancy were analysed over a period of two years in the department of obstetrics and gynaecology, Niloufer hospital Hyderabad. Out of 50 cases, 34 underwent laparotomy and 16 underwent laparoscopy. Comparison made for immediate outcome, intraoperative and postoperative complications and duration of surgery. Ectopic pregnancy was diagnosed by the presenting complaints, clinical and gynaecological examination, positive pregnancy test and transvaginal ultrasonography. After the surgery specimen (Excised ectopic pregnancy) was sent for histopathological examination for confirmation of diagnosis.

RESULTS: Maximum incidence of ectopic pregnancy was seen in the age group of 31-44 years and in muliparous women. Maximum number of patients presented with pain abdomen, delayed period and bleeding per vaginum ( $p$ value $<0.0000001$ significant). The duration of surgery in laparoscopy group was 70-80 minutes and in laparatomy 35-45 minutes. The mean duration of hospitalization was significantly shorter in laparoscopy group ( 3 days) when compared to laparatomy group (8 days).Surgical blood loss was more in laparatomy group $(150-200 \mathrm{ml})$ when compared with laparoscopy group (50-80 ml). All 34 patients in laparatomy group required postoperative analgesia and only one patient required analgesia in laparoscopy group.

CONCLUSION: Laparoscopic surgical management of ectopic pregnancy was more beneficial over laparatomy in terms of less blood loss, decreased need for postoperative analgesia, shorter duration of hospital stay and faster recovery with cosmetically better scar.

KEYWORDS: Ectopic Pregnancy, Laparatomy, Laparoscopy.

HOW TO CITE THIS ARTICLE: K. Saraswathi, M. Shailaja Prasad, B. Kiran Kumari. "Tubal Ectopic Pregnancy: Comparative Study of Laparoscopy vs Laparotomy”. Journal of Evolution of Medical and Dental Sciences 2015; Vol. 4, Issue 89, November 05; Page: 15447-15449, DOI: 10.14260/jemds/2015/2206.

INTRODUCTION: Ectopic pregnancy is one of the obstetric complications of early pregnancy wherein the fertilized ovum is implanted and develops outside the normal uterine cavity. Commonest site of ectopic pregnancy is found in the ampullary part of the fallopian tube.

The incidence of ectopic pregnancy has increased all over the world. from $0.5 \%$ to present day $1-2 \%$ due to increased prevalence of chronic pelvic inflammatory disease, tubal plastic surgeries and ovulation induction. With early diagnosis and therapy, advances in anesthesia, antibiotics and blood transfusions, mortality has reduced significantly.

There are several modalities of treating ectopic pregnancy from medical management, conservative surgical modalities (Salpingostomy and salpingotomy) and more radical treatment of salpingectomy. Surgical methods can be done through laparatomy or laparoscopy.

The choice of treatment depends on clinical presentation, haemodynamic status of the patient, availability of laparoscopic equipment, surgeon's choice and concern for future fertility.

Financial or Other, Competing Interest: None.

Submission 10-10-2015, Peer Review 11-10-2015,

Acceptance 21-10-2015, Published 05-11-2015.

Corresponding Author:

Dr. K. Saraswathi,

Associate Professor,

Obstetrics and Gynaecology,

Niloufer Hospital. Hyderabad,

Telangana State.

E-mail: saraswathikokkirala@gmail.com

DOI:10.14260/jemds/2015/2206.
A comparative study of laparoscopy versus laparatomy for the treatment of ectopic pregnancy has been conducted for a two year period July 2010 to June 2012 at niloufer hospital.

In this study comparison is made between laparoscopy and laparatomy with reference to duration of procedure, intraoperative and postoperative complications, duration of stay in hospital. Incidence and risk factors for ectopic pregnancy were studied.

METHODS: In this study 50 cases of ectopic pregnancy were analysed over a period of 2 years for comparison between laparatomy and laparoscopic intervention with regard to the patient's immediate outcome, intraoperative and postoperative complications and duration of surgery.

These patients were admitted through outpatient or emergency departments. The diagnosis of ectopic pregnancy was based on symptomatology, physical and gynaecological examination, positive pregnancy test or positive serum beta HCG, transvaginal ultrasonography showing empty uterus, with or without adnexal mass and intra-abdominal fluid collection. Once the ectopic pregnancy has been diagnosed the patients were counseled regarding the various methods of management and their advantages and risks.

If the patient required surgical intervention the choice of the patient to undergo laparotomy or laparoscopy depended on the haemodynamic status of the patient, previous abdominal surgeries and on the availability of the laparoscopic surgeon. Preoperative preparation included surgical profile and informed consent. Blood and blood products were made available. 
Operative laparoscopy: Operative laparoscopy was performed under general anesthesia. After creating pneumoperitoneum a $10 \mathrm{~mm}$ laparoscope was introduced through a cannula in intraumbilical or subumbilical incision and video camera is attached and connected to monitor. After ectopic pregnancy was confirmed two $5 \mathrm{~mm}$ and a10 $\mathrm{mm}$ ancillary ports were made of the in right and left lower quadrants using direct visualization and transillumination to avoid inferior epigastric vessels.

Using a large bore suction irrigator blood and blood clots were evacuated. Laparoscopic total salpingectomy was performed by progressive coagulation and cutting of mesosalpinx starting from the fimbrial end towards the isthmus. Separated tube was retrieved from $10 \mathrm{~mm}$ port and sent for histopathological confirmation of ectopic pregnancy. Condition of the contralateral tube verified. Haemostasis verified prior to the withdrawal of pneumoperitoneum and laparoscope.

Operative time and blood loss noted Postoperative care included monitoring vital data and input output chart was maintained. Analgesia given for pain relief included diclofenac sodium or tramodol. After bowel sounds returned patients were put on oral fluids followed by soft diet. Patients were advised early ambulation from first postoperative day. Discharge of patient was done on third or fourth postoperative day and outpatient follow up advised.

Laparatomy: Laparatomy was performed under spinal or general anesthesiasuprapubicpfannenstiel incision used to open the abdomen and salpingectomy done by standard surgical technique and specimen sent for histopathological examination. Like in laparoscopic technique, duration of surgery, amount of blood loss and other intraoperative complications noted.

RESULTS: In the study 50 cases of ectopic pregnancy were analysed over a period of 2 years. Out of 50 cases 34 underwent laparatomy and 16 laparoscopic surgery. Maximum incidence of ectopic was seen in the age group of 31 to 44 years and in multiparous women. It has been noted that maximum number of patients presented with pain abdomen $(92 \%)$, bleeding per vaginum $(80 \%)$ and delayed period (86\%) (Table1). History of pelvic inflammatory disease was present in $20 \%$ cases, history of previous abortion in $20 \%$ cases previous tubal surgery in $12 \%$ cases and history of treatment for infertility in $8 \%$ of cases. History of previous ectopic pregnancy was present in $8 \%$ of cases (Table 2).

Operative findings revealed that in 34 cases right fallopian tube was involved and in 16 cases left fallopian tube was the site of ectopic pregnancy. The study showed ruptured ectopic in 34 cases (68\%) and all 34 cases showed variable amount of haemoperitoneum.

Two cases with previous history of ectopic had absent tube on the opposite side. Estimated surgical blood loss for laparoscopy was 50-80 ml and for laparatomy it was 150-200 $\mathrm{ml}$. The operating time for laparoscopy was 70-80 minutes depending upon the experience of the laparoscopic surgeon and 35-45 minutes for laparotomy.

The average duration of stay in the hospital for laparoscopy was significantly shorter (3 days) and for laparatomy it was 8 days.(Table3). Blood transfusion was required in most of the ruptured ectopic pregnancies depending on the haemodynamic status of the patient. All 34 patients of the laparotomy group required analgesia postoperatively where as only one patient required in laparoscopy group. Abdominal wound sepsis was found in 2 cases (4\%) of laparotomy group and none of the cases reported sepsis in the laparoscopy group.

DISCUSSION: In this study emphasis was laid on comparative study of surgical management of ectopic pregnancy with regard to laparoscopy versus laparatomy. The incidence of ectopic pregnancy is $1-2 \%$ and the incidence in our study was $0.6 \%$ as cases are being treated in private and public health institutions available in our city.

It has been observed that older age women(30-44 years) are at three fold increased risk of ectopic pregnancy due to abnormal blastocyst implantation. Increased incidence in younger age group is being reported due to STD's and PID. Sepilian.(1) reported 3-4 fold increased risk in the age group of 3044 years. M Nabil E L Tabbakh.(2) reported 50\% cases in 21-32 group.

Multiparous women accounted for $72 \%$ and nulliparous for 28\% similar report was given by M Nabil EL Tabakh.(2) from Hadi Hospital and El Rashed Hospital Kuwait with nulliparous constituting $26 \%$ and multiparous $64 \%$. Bagiratee et al.(3) reported incidence of $26.7 \%$ in nulliparous and $73.3 \%$ in multiparous women. With regard to clinical presentation commonest presenting complaints were lower abdominal pain (92\%), delayed period (86\%) and bleeding per vagina $82 \%$ ) noted in our study correlated with study done by M. Nabil EL Tababakh who reported abdominal pain in $96 \%$, short period of amenorrhoea in $89.1 \%$ and vaginal bleeding in 79.1.

TanvirKopani, ArbenRrugia.(4) also reported similar incidence of presenting complaints. Major risk factors noted were history of PID (20\%), tubal surgeries (20\%), previous ectopic (8\%) and treatment for infertility (8\%). Shaista Aziz, Bothaina Alwafi.(5) reported previous abortion (37.8\%), IUCD insitu (4.5\%), previous pelvic surgery (18\%), infertility (19\%) and recurrent ectopic (9\%) as risk factors. Right fallopian tube $(68 \%)$ was predominantly involved in our study. Study conducted at Hadi hospital showed similar incidence with 79.2\% cases in right fallopian tube.

Most common site of ectopic in fallopian tube was ampullary region (88\%) in our study, Study conducted in Hadi hospital and E L Rashed hospital in Kuwait reported 96.7\% ectopics in ampullary region. Ruptured tube with haemoperitoneum was found in $68 \%$ of patients. Yuen (1997) prince Wales hospital reported haemoperitoneum in $75 \%$ of cases.

Mean duration of surgery was 75 minutes in laparoscopy and 40 minutes in laparatomy. Duration is variable for laparoscopic surgery because of many factors like availability of laparoscopic facilities and expertise of surgical team. M Nabil El Tabbakar reported operation time for laparoscopy as $66.46 \pm 19.7$ minutes and for laparotomy $72.52 \pm 20.01$ minutes. Xiang.(6) reported operation time for laparoscopically treated patients to be shortened when compared to laparatomy.

Mean duration of stay at hospital is 3 days (2-5days) for laparoscopic surgery and for laparatomy is 8 days (7-9days). Similar findings were reported by Yuen with duration of hospitalization ranging from 2-9 days for laparatomy versus 5.1 day for laparoscopy. Grey et al.(7) 1995 reported shorter duration of hospital stay of 1 and 2 days for laparoscopic surgery and 3 and 5 days for laparatomy.

In patients undergoing laparoscopic intervention 5 cases required blood transfusion and in patients who underwent 
laparatomy 20 patients required blood transfusion based on the haemodynamic status of the patient. Yuen, Mrs rogi Chary. ${ }^{(8)}$ reported that only $7 \%$ of patients in laparoscopy group required blood transfusion.

Intraoperative surgical blood loss was $50-80 \mathrm{ml}$ in laparoscopy group compared to $150-200 \mathrm{ml}$ in laparatomy. Most of the postoperative complications were seen in laparatomy cases. Yuen, Mrs Rogichary.(8) reported laparoscopic group was asssociated with significant reduction of postoperative analgesia requirement and reduction of postoperative morbidity.

Early ambulation was observed in laparoscopic patients group in whom $95 \%$ were ambulatory on first postoperative day and $5 \%$ on second postoperative day. In patients who underwent laparatomy $60-65 \%$ were ambulatory on first postoperative day, $25 \%$ on second postoperative day and remaining on third postoperative day. Postoperative pain and requirement of analgesics more for laparotomy treated patients.

CONCLUSION: If laparoscopic equipment and surgical expertise are available laparoscopy should be the gold standard for the surgical treatment of ectopic pregnancy. Our study also confirms that it offers less surgical blood loss, less need for blood transfusion, decreased need for postoperative analgesia, shorter duration of hospital stay, faster recovery, cosmetically better scar and more economical. Where laparoscopic facilities or expertise are not available or if patient is haemodnamically unstable or in the event of extensive pelvic adhesions where it is impossible to view the ectopic pregnancy, conventional laparatomy will be the choice of surgery. Both laparatomy and lapaoscpy are comparable with regard to future fertility and recurrence of ectopic pregnancy.

\begin{tabular}{|c|c|c|}
\hline $\begin{array}{c}\text { Chief } \\
\text { Complaints } \\
\end{array}$ & $\begin{array}{c}\text { No. of } \\
\text { Patients }\end{array}$ & $\begin{array}{c}\text { Total } \\
\text { Percentage }\end{array}$ \\
\hline Missed period & 43 & $86 \%$ \\
\hline $\begin{array}{l}\text { Lowerabdominal } \\
\text { pain }\end{array}$ & 46 & $92 \%$ \\
\hline $\begin{array}{c}\text { Bleeding/spotting } \\
\text { per vagina }\end{array}$ & 40 & $80 \%$ \\
\hline Giddiness & 4 & $8 \%$ \\
\hline Shock & 3 & $6 \%$ \\
\hline $\begin{array}{l}\text { Nausea and } \\
\text { vomiting }\end{array}$ & 5 & $10 \%$ \\
\hline \multicolumn{3}{|c|}{$\begin{array}{c}\text { Table 1: Symptomatology : patients presented } \\
\text { with more than one complaints }\end{array}$} \\
\hline
\end{tabular}

\begin{tabular}{|c|c|c|}
\hline $\begin{array}{c}\text { Risk } \\
\text { Factors } \\
\end{array}$ & $\begin{array}{c}\text { No of } \\
\text { Patients }\end{array}$ & $\begin{array}{c}\text { Total } \\
\text { Percentage }\end{array}$ \\
\hline $\begin{array}{l}\text { H/o pelvic inflammatory } \\
\text { disease }\end{array}$ & 10 & $20 \%$ \\
\hline $\begin{array}{l}\text { History of Previous ectopic } \\
\text { pregnancy }\end{array}$ & 4 & $8 \%$ \\
\hline H/o tubal surgeries & 6 & $12 \%$ \\
\hline $\begin{array}{l}\text { H/o Treatment for } \\
\text { infertility }\end{array}$ & 4 & $8 \%$ \\
\hline H/o previous abortion & 10 & $20 \%$ \\
\hline H/o previous IUCD & 1 & $2 \%$ \\
\hline H/o OC pills & - & - \\
\hline H/o smoking & - & - \\
\hline \multicolumn{3}{|c|}{$\begin{array}{l}\text { Table 2: Risk factors : distribution according } \\
\text { to riskfactors for ectopic pregnancies }\end{array}$} \\
\hline
\end{tabular}

\section{REFERENCES:}

1. Septilian V.P,wood.E ectopic pregnancy 2009 eMedicine Obstetrics \& Gynacecology. http://emedicinemedscope.com/article/258768- overview.

2. M.Nabil, EL Tabbakh, M.Shareef El Sayes Tubal ectopic pregnancy;laparoscopic vs laparato my June 282011 OBGYN. Net.

3. J.Bagiratee,N.singh, J.Moodley A descriptive analysis of women presenting with ectopic pregnencies at King Edward VIII Hospital,Durban,South Africa-International Jounal of Gynecology \& Obstetrics Oct 2009 volume 207,Supplement 2,pages 5543-5544.

4. Fatmirkopani,arbenRrugia et al: Ectopic pregnancy comparison of different treatments: J. Prenat. Med.2010, Apr_Jun(2):30-34.

5. Haista Aziz, Bothaina Al Wafi, Hussain Al Swadi: Frequency of ectopic pregnancy in a medical centre, Kingdom of Saudi Arabia JPMA 61:221;2011

6. Xiang ,Xd Tane,YQ,Mao,J.F.A comparision of laparoscopic surgery and Laparotomy in the Treatment of Ectopic Pregnancy, Singapore Med J.1999 Feb;40(2):88-90.

7. Gray D T, Thorburn J, Lundorff P, Strandell A, Lindblomm B: A cost-effectiveness study of a randomized trial of laparoscopy versus laparatomy for ectopic pregnancy.Lancet.1995; 345;1139-1143.

8. Yuen P M, Rogers M S, Chang A: A review of laparoscopy and laparatomy in the management of tubal pregnancy, hongkong medical journal1997jun:3(2):153-15.

\begin{tabular}{|c|c|c|}
\hline Type of Surgery & Duration of Stay & Mean Duration \\
\hline Laparoscopy & $2-5$ days & 3 days \\
\hline Laparotomy & $7-9$ days & 8 days \\
\hline \multicolumn{3}{|c|}{ Table 3 : Duration of Surgery } \\
\hline
\end{tabular}

\begin{tabular}{|c|c|c|}
\hline Type of Complication & Laparoscopies & Lapartomy \\
\hline Heamorrhage & - & - \\
\hline Pyrexia & - & 5 \\
\hline Anaesthesia & - & 1 \\
\hline Wound sepsis & - & 2 \\
\hline Pulmonary problems & - & 3 \\
\hline Urinarytractinfection & 1 & 2 \\
\hline Wound dehesion & - & - \\
\hline Burst abdomen & - & - \\
\hline Analgesic requirement & 1 & 34 \\
\hline \multicolumn{2}{|c|}{ Table 4: Early post-operative complications } \\
\hline
\end{tabular}

